\title{
Epidemic activity of respiratory syncytial virus is related to temperature and rainfall in equatorial tropical countries
}

\author{
N. GAMBA-SANCHEZ ${ }^{1,2}$, C. E. RODRIGUEZ-MARTINEZ $Z^{3,4,5 *}$ AND \\ M. P. SOSSA-BRICEÑO ${ }^{6}$ \\ ${ }^{1}$ Department of Pediatrics, Fundacion Hospital de la Misericordia, Bogota, Colombia \\ ${ }^{2}$ Department of Pediatrics, Clinica Infantil Colsubsidio, Bogota, Colombia \\ ${ }^{3}$ Department of Pediatrics, School of Medicine, Universidad Nacional de Colombia, Bogota, Colombia \\ ${ }^{4}$ Department of Pediatric Pulmonology and Pediatric Critical Care Medicine, School of Medicine, Universidad El \\ Bosque, Bogota, Colombia \\ ${ }^{5}$ Research Unit, Military Hospital of Colombia, Bogota, Colombia \\ ${ }^{6}$ Department of Internal Medicine, School of Medicine, Universidad Nacional de Colombia, Bogota, Colombia
}

Received 20 July 2015; Final revision 1 January 2016; Accepted 27 January 2016;

first published online 18 February 2016

\section{SUMMARY}

Although viral acute lower respiratory infections (ALRIs) are a major public health problem in tropical low- and middle-income countries (LMICs), and there is growing evidence showing their relationship with meteorological parameters, studies performed in these countries are scarce. In an analytical crosssectional study, we determined which of the main meteorological parameters (temperature, absolute humidity, rainfall, wind speed, and solar radiation) predicted respiratory syncytial virus (RSV) activity in a population of hospitalized children with ALRI during a 5-year period, from January 2009 to December 2013. Out of a total of 4559 children included in the study (mean age $9 \cdot 2 \pm 8 \cdot 5$ months), 2953 (64.8\%) presented RSV infection during the 3-month period from March to May. In the multivariate analysis, after controlling for absolute humidity, wind speed, and solar radiation, temperature [incidence rate ratio (IRR) $2 \cdot 25,95 \%$ confidence interval (CI) $1 \cdot 11-4 \cdot 53, P=0 \cdot 024$ ], and rainfall (IRR $1 \cdot 01,95 \%$ CI $1 \cdot 00-1 \cdot 02, P=0 \cdot 044)$ were independently associated with the monthly number of RSV infections. In conclusion, in Bogota, the capital of a tropical LMIC lying slightly above the equator, RSV activity peaks in the 3-month period from March to May, the main rainy period of the year in the city. In addition, rainfall and temperature are the two most important meteorological parameters that are independently associated with RSV activity in hospitalized children with ALRI in the city.

Key words: Children, climatic factors, epidemic, respiratory syncytial virus.

\section{INTRODUCTION}

Viral acute lower respiratory infections (ALRIs) are a major public health problem because they are widely considered to be the main cause of morbidity and mortality, especially in children aged $<5$ years [1].

\footnotetext{
* Author for correspondence: Dr C. E. Rodriguez-Martinez, Avenida Calle 127 No. 20-78, Bogota, Colombia.

(Email: carerodriguezmar@unal.edu.co)
}

Although ALRI poses a significant health problem in high-income countries, it is of even greater concern in low- and middle-income countries (LMICs). The problem is of such magnitude that ALRI is recognized as being the main cause of death in infants and children living in LMIC [2].

It is well known that respiratory syncytial virus (RSV) is the leading cause of ALRIs and hospitalization in young children but especially so in infants [3]. The most common clinical pattern of illness seen with 
RSV infection in infants is bronchiolitis, a clinical syndrome characterized by the obstruction of expiratory airflow usually preceded by an upper respiratory tract infection. It has been reported that RSV is the most commonly identified virus in hospitalized infants with bronchiolitis, with detection rates reaching up to $70-85 \%$ during seasonal winter epidemics [4]. Recent evidence has strongly suggested that there is an association between some meteorological parameters and RSV activity in the community [5]. It has been reported that RSV activity in cooler climates is inversely related to temperature, possibly due to the increased stability of RSV in secretions in cold environments [5]. By contrast, in tropical countries although RSV activity has been shown to be continuous throughout the entire year, it has been reported to be directly related to ambient temperature, absolute humidity, and rainfall [5-7]. Information on the meteorological parameters associated with RSV activity could be useful in timing preventive strategies to target high-risk populations during high-occurrence periods of RSV activity. However, few researchers have addressed the problem in tropical LMICs, where ALRIs are an even a greater public health problem than in high-income countries. In the same manner, some of the previous work has failed to address the problem for sufficient time to allow the comparison of the consistency of trends in seasonality of RSV over time. Specifically, in an exploratory study reported by our group, we assessed the association between RSV activity and meteorological parameters during a period of only 18 months [7].

The aim of the present study was to assess the longterm association between meteorological parameters and RSV activity in a population of children hospitalized due to ALRI in Bogota, Colombia, a tropical LMIC.

\section{MATERIAL AND METHODS}

\section{Study site}

The geographical and meteorological conditions of Bogota, the Colombian capital, have been described in a previous study published by our group [7]. In brief, the city is located at an elevation of about $2650 \mathrm{~m}$ above sea level, on a mountain-rimmed plateau high in the Andes Mountains, lying only $4^{\circ} 36^{\prime}$ north of the equator. Bogota has a subtropical highland climate. Because of its elevation and its proximity to the equator, the city has a temperature relatively consistent throughout the year of about $14.5^{\circ} \mathrm{C}$, but weather conditions can change markedly from one hour to the next, with variations during the day ranging between $6{ }^{\circ} \mathrm{C}$ and $19^{\circ} \mathrm{C}$ on cloudless days, and between $10^{\circ} \mathrm{C}$ and $18{ }^{\circ} \mathrm{C}$ on extremely rainy days. The warmest month is March, with a maximum temperature of $19.7^{\circ} \mathrm{C}$. The coldest nights occur in January, with an average of $7 \cdot 6^{\circ} \mathrm{C}$ in the city. The average annual absolute humidity is $10 \mathrm{~g} / \mathrm{m}^{3}$ and average monthly absolute humidity ranges from $9 \mathrm{~g} / \mathrm{m}^{3}$ in February to $10.5 \mathrm{~g} / \mathrm{m}^{3}$ in November. Mean annual rainfall in the city is about $672 \mathrm{~mm}$ and the mean annual wind speed is $1.5 \mathrm{~m} / \mathrm{s}$. The city typically experiences only two seasons: dry and wet, with the dry season running from December to March and from June to August, and the rainy season running approximately from March to May and from September to November [7]. The Fundacion Hospital de La Misericordia is a university-based children's hospital located in the metropolitan area of Bogota. The hospital has 287 beds, and functions as a tertiary referral centre for the city of Bogota (7 363782 inhabitants) admitting around 12000 children, and receiving more than 60000 emergency room visits per year.

\section{Study design and procedures}

An analytical cross-sectional study was conducted during a 5-year period, from January 2009 to December 2013 in a consecutive sample of patients aged $<3$ years hospitalized in the Fundacion Hospital de La Misericordia with a diagnosis of ALRI. In our institution, patients with ALRI who are sick enough to be admitted to the hospital are tested for RSV using a rapid immunoassay method (Abbott Test Pack RSV Rapid Diagnostic kit; Abbott, USA).

In order to meet the objectives of the study, we collected demographic and clinical data, and RSVpositive cases were added on a monthly basis in order to estimate the number of RSV infections for each calendar month during the monitoring period. We defined continuous RSV activity as a percentage of at least $10 \%$ of RSV samples positive throughout the year [5].

\section{Meteorological parameters}

Temperature $\left({ }^{\circ} \mathrm{C}\right)$, relative humidity $(\%)$, rainfall $(\mathrm{mm})$, wind speed $(\mathrm{m} / \mathrm{s})$, and solar radiation $\left(\mathrm{W} / \mathrm{m}^{2}\right)$ were routinely measured at Bogota's Air Quality Network (BAQN), which consists of 14 stations distributed throughout the city that have been 
monitoring meteorological parameters since 1997 [8]. The average monthly absolute humidity $\left(\mathrm{g} / \mathrm{m}^{3}\right)$ was calculated based on temperature and relative humidity values. These data were available on a daily basis from 1 January 2009 to 31 December 2013, and for each meteorological variable, a monthly average was calculated.

\section{Statistical analysis}

Continuous variables are given as mean \pm standard deviation (s.D.) or median (interquartile range), as appropriate. Categorical variables are presented as numbers (percentage).

The bivariate correlation between the monthly number of RSV infections and meteorological parameters was analysed using Spearman's rank correlation coefficient. In the same way as in our previous exploratory study, to identify predictor meteorological parameters independently linked to the monthly number of RSV infections, we used a negative binomial regression to allow for overdispersion in the distribution of the monthly number of RSV infections. This regression technique, which can be considered to be a generalization of Poisson regression, can be used for overdispersed count data, because it has the same structure as Poisson regression and it has an extra parameter to model the overdispersion [9]. However, this model assumes that the process that generates the events are independent and because this may not be the case with our data due to a possible autocorrelation between the observations, we also adjusted generalized linear models (GLMs) using the Newey-West estimator of variance to correct for any violation in the assumption of independence [10]. In order to avoid collinearity that might cause the affected estimates to be unstable and with high standard errors, when we found high and significant bivariate correlation between pairs of predictor variables, we performed additional regression models excluding in each model one of the two variables being correlated. Regression results are reported as incidence rate ratios (IRRs) and their respective 95\% confidence intervals (CIs). All statistical tests were two-tailed, and the significance level used was $P<0 \cdot 05$. The data were analysed with Stata v. 12.0 (Stata Corporation, USA).

\section{Ethical standards}

The authors assert that all procedures contributing to this work comply with the ethical standards of the relevant national and institutional committees on human experimentation and with the Helsinki Declaration of 1975, as revised in 2008.

\section{RESULTS}

\section{Study population}

A total of 13488 samples of children hospitalized with a diagnosis of ALRI were tested during the 5-year monitoring period, of whom 4559 (33.8\%) were analysed in the study because they tested positive for RSV. The mean (s.D.) age of the patients analysed in the study was $9 \cdot 2 \pm 8 \cdot 5$ months.

\section{Examination of monthly RSV activity and meteorological parameters}

Number of monthly RSV infections during the monitoring period, along with monthly average of rainfall, temperature, absolute humidity, wind speed, and solar radiation are depicted in Figure 1. On analysing the data about the monthly RSV activity during the monitoring period, we found that RSV activity was continuous throughout the 5-year period, peaking each year in the 3-month period from March to May, the main rainy period of the year in the city.

\section{Association between meteorological parameters and monthly RSV activity}

Temperature and rainfall were the only two meteorological parameters that were significantly associated with the monthly number of RSV infections in the bivariate analysis (Table 1). In the multivariate analysis, after controlling for absolute humidity, wind speed, and solar radiation, temperature (IRR $2 \cdot 25,95 \%$ CI $1 \cdot 11-4.53, P=0.024)$ and rainfall (IRR $1 \cdot 01,95 \%$ CI $1 \cdot 00-1 \cdot 02, P=0.044)$ were independently associated with the monthly number of RSV infections (Table 2). The proportion of variance of the monthly number of RSV infections that is explained by the predictors was $2 \cdot 5 \%$ (pseudo- $R^{2}=0 \cdot 0255$ ). As mentioned, due to the high and significant bivariate correlation between rainfall and absolute humidity, and between other pairs of predictor variables, we performed additional negative binomial regression models excluding in each model one of the two variables being correlated. Results were similar in all these additional analyses: temperature and/or rainfall were the only predictor variables independently associated with the monthly number of RSV infections (results not 

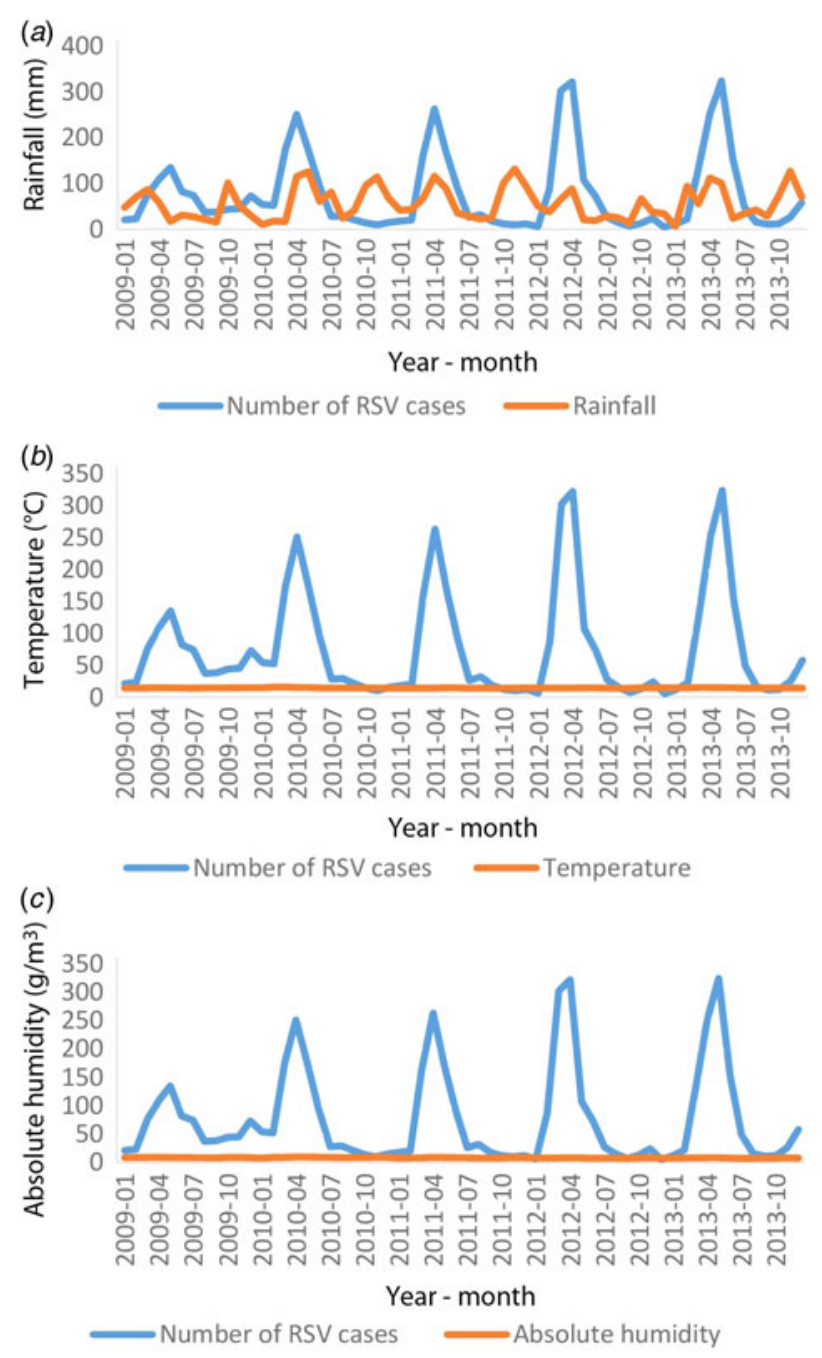

Fig. 1. Monthly number of respiratory syncytial virus (RSV) infections, and monthly variation of $(a)$ rainfall, $(b)$ temperature, $(c)$ absolute humidity. The x-axis shows the date (covering the period from January 2009 to December 2013). The y-axis shows the monthly number of RSV infections and the average monthly rainfall, temperature, and absolute humidity.

shown). After adjusting GLM using the Newey-West estimator of variance, temperature (IRR $2 \cdot 31,95 \% \mathrm{CI}$ $1 \cdot 77-3.03, P<0 \cdot 001)$ and rainfall (IRR $1.01,95 \% \mathrm{CI}$ $1 \cdot 00-1 \cdot 02, P<0 \cdot 001)$ were also the only independent predictors of the number of monthly RSV infections.

\section{DISCUSSION}

The present study shows that in Bogota, a moderate-altitude city lying slightly above the equator, RSV shows activity throughout the year, peaking in the 3-month period from March to May, the main rainy period of the year in the city. In addition, rainfall and temperature are the two most important meteorological parameters that are independently associated with RSV activity in hospitalized children with ALRI in the city.

We are confident that the present findings have gone some way towards enhancing our understanding of how in Bogota, and probably other similar tropical regions north of the equator, RSV activity can be predicted by meteorological parameters that are easily and routinely measured. This knowledge could be useful in the development of specific interventions aimed at ameliorating or preventing the impact of RSV activity in high-risk group of patients, especially in those regions which do not perform local virological surveillance, by anticipating the periods of greatest RSV circulation according to the continuous monitoring of meteorological variables, which is routinely performed in several tropical cities worldwide. Specifically, the association between local RSV activity with meteorological data, and traditional respiratory viral surveillance information could provide, in conjunction, information on when to institute passive immunization against RSV and when to withdraw it. Likewise, this knowledge can provide valuable data that can be used for formulation or reinforcement of interventions aimed to limit the nosocomial spread of RSV, such as education of medical personnel and family members on hand decontamination, wearing masks when anticipating exposure to aerosolized secretions while performing patient care activities, cohorting of affected patients, and surveillance for the onset of RSV season [11].

The findings of the present study are in good agreement with previously published data showing that in regions close to the equator epidemic activity of RSV is associated with higher relative humidity and temperature, and even modest shifts northward or southward from the equator result in an inverse relationship between humidity, temperature, and RSV activity, due to the drier, colder air [5]. Although absolute humidity was not an independent predictor of the RSV activity in our negative binomial regression model, it showed a positive and significant association with rainfall in the bivariate analysis (Spearman's $\rho=0 \cdot 603, P<0 \cdot 001$ ). Our findings are also consistent with previous studies performed in equatorial zones and in other tropical and subtropical countries that have shown that epidemic RSV activity is associated with the rainy period and the relative humidity of the respective cities [3]. Likewise, the results of our study are in line with those of two previous 
Table 1. Correlations between the number of monthly respiratory syncytial virus (RSV) infections and meteorological variables

\begin{tabular}{lcccccc}
\hline \hline Variable & RSV infections & Wind speed & Rainfall & Temperature & Absolute humidity & Solar radiation \\
\hline RSV infections, $n$ & $1 \cdot 000$ & $-0 \cdot 170$ & $0 \cdot 309^{*}$ & $0 \cdot 370^{* *}$ & $0 \cdot 307^{*}$ & $-0 \cdot 150$ \\
Wind speed & $-0 \cdot 170$ & $1 \cdot 000$ & $-0 \cdot 708^{* *}$ & $-0 \cdot 079$ & $-0 \cdot 706^{* *}$ & $0 \cdot 350^{* *}$ \\
Rainfall & $0 \cdot 309^{*}$ & $-0 \cdot 708^{* *}$ & $1 \cdot 000$ & $-0 \cdot 002$ & $0 \cdot 544^{* *}$ & $-0 \cdot 479^{* *}$ \\
Temperature & $0 \cdot 370^{* *}$ & $-0 \cdot 079$ & $-0 \cdot 002$ & $1 \cdot 000$ & $0 \cdot 437^{* *}$ & $0 \cdot 047$ \\
Absolute humidity & $0 \cdot 182$ & $0 \cdot 754^{* *}$ & $0 \cdot 603^{* *}$ & $0 \cdot 065$ & $1 \cdot 000$ & $-0 \cdot 479^{* *}$ \\
Solar radiation & $-0 \cdot 150$ & $0 \cdot 350^{* *}$ & $-0 \cdot 479^{* *}$ & $0 \cdot 047$ & $-0 \cdot 416^{* *}$ & $1 \cdot 000$ \\
\hline \hline
\end{tabular}

* Correlation significant at $0 \cdot 05$ level.

** Correlation significant at 0.01 level.

Table 2. Predictors of the number of monthly respiratory syncytial virus infections in multivariate analysis

\begin{tabular}{lll}
\hline \hline Variable & IRR $(95 \% \mathrm{CI})$ & $P$ value \\
\hline Wind speed & $1 \cdot 56(0 \cdot 22-11 \cdot 26)$ & $0 \cdot 660$ \\
Rainfall & $1 \cdot 01(1 \cdot 00-1 \cdot 02)$ & $\mathbf{0} \cdot \mathbf{0 4 4}$ \\
Temperature & $2 \cdot 25(1 \cdot 11-4 \cdot 53)$ & $\mathbf{0 \cdot 0 2 4}$ \\
Absolute humidity & $1 \cdot 10(0 \cdot 53-2 \cdot 31)$ & $0 \cdot 791$ \\
Solar radiation & $0.99(0.98-1 \cdot 01)$ & 0.982 \\
\hline \hline
\end{tabular}

IRR, Incidence rate ratio; CI, confidence interval.

local studies that also investigated the epidemiology of RSV in Bogota. In an exploratory study reported by our group, we found that $77 \cdot 1 \%$ of the total of RSV infections occurred during the 3-month period from March to May. Moreover, we found that monthly average temperature and rainfall were independently associated with the monthly number of RSV infections [7]. In a second study, published almost 20 years ago, monthly RSV activity and its relationship with meteorological parameters in Bogota during a 5-years follow-up period were evaluated. The authors of this study found that although RSV activity was continuous throughout the study period, it clearly peaked each during the first rainy period of the year in the city (more than $50 \%$ of the total number of bronchiolitis cases were diagnosed each year during the 3-month period from April to June). Upon analysing the association between RSV activity and meteorological parameters, the authors found that RSV activity was positively associated with rainfall and with lower intra-day temperature variations during the monitoring period [12]. This latter finding is in line with our results that showed that temperature is one of the two meteorological parameters that are independently associated with RSV activity. This is because although it is believed that the rainy season is colder than the drier season, during the drier season the temperatures are high during the day but drop below $0{ }^{\circ} \mathrm{C}$ at night and early morning, resulting in lower mean temperatures compared to the rainy season. It is worth noting that RSV activity tends to coincide with only the first of the two annual rainy seasons of the city (Fig. 1). Although we do not know the exact cause of this partial coincidence, we speculate that it is related to the greater average monthly rainfall and temperature in the first rainy season compared to the second one.

The association between RSV activity and precipitation and temperature could be explained by at least two mechanisms. First, high rainfall and high temperatures can favour the replication, stability, survival and therefore transmission of the virus in the environment [13-15]. In this regard, it has been proposed that RSV replicates better in regions north of equator when the temperature change is associated with rain and in regions south of the equator when the temperature change is associated with the dry season. The explanation for this discrepancy is that RSV stability is biphasic under different humidity concentrations with two peaks at which it is more stable, one low and one high [16]. In the same manner, Yusuf et al. [6] proposed that in tropical and sub-tropical areas, high humidity and stable high temperatures facilitate RSV to be sustained in large-particle aerosols well enough to allow year-round transmission of the virus. Second, specific climatic conditions can influence the susceptibility of the host to presenting ALRIs through the modification of certain physiological responses. For example, solar radiation can interfere with RSV activity by stimulating vitamin D production, increasing metabolism and inducing 
the formation of defensive peptides by some of the vitamin D metabolites, which have been shown to have direct antiviral activity by means of the impairment in the ability of viruses to infect cells [17].

We are aware that our research may have two limitations. The first is that the association between meteorological parameters and the activity of RSV could be influenced by many confounding factors including the fact that RSV is more easily transmitted from person to person when staying indoors during the rainy season [18]. Additionally, other confounding factors could comprise other environmental factors, air pollution levels, social interaction between affected persons, viral characteristics, and host susceptibility. However, the similarity of our findings with those of other researchers who investigated that association, and who included predictor variables other than the ones included in our model, suggests that confounding plays a minimal role. The second is that assessment of RSV activity in a hospitalized population of children with ALRI could only reflect the more severe cases of RSV disease, probably not capturing the full spectrum of disease severity in the community. However, the consistency of our findings with those of earlier surveillance epidemiological reports that included children with the full spectrum of RSV disease [19], suggests that our findings could be representative of RSV activity in the community. The main strengths of our study are that it adds to a growing body of literature on the association between meteorological parameters and RSV activity in a tropical region north of the equator for long enough to allow comparison of the consistency of trends in seasonality of RSV over time, and that it confirms initial findings from previous exploratory studies.

In conclusion our work has led us to conclude that in Bogota, the capital of a tropical LMIC lying slightly above the equator, RSV shows activity throughout the year, peaking in the 3-month period from March to May, the main rainy period of the year in the city. Additionally, rainfall and temperature are the two most important meteorological parameters that are independently associated with RSV activity in hospitalized children with ALRI in the city.

\section{ACKNOWLEDGEMENTS}

The authors thank Nestor Yesid Rojas, PhD, Associate Professor of Chemical Engineering, Universidad Nacional de Colombia, and Edison
Ortiz, MSc for their help with the meteorological variables

This research received no specific grant from any funding agency, commercial or not-for-profit sectors.

\section{DECLARATION OF INTEREST}

None.

\section{REFERENCES}

1. Bardach A. et al. Systematic review and meta-analyses of respiratory syncytial virus infection epidemiology in Latin America. Reviews in Medical Virology 2014; 24: 76-89.

2. Nair H, et al. Global and regional burden of hospital admissions for severe acute lower respiratory infections in young children in 2010: a systematic analysis. Lancet 2013; 381: 1380-1390.

3. Weber MW, Mulholland EK, Greenwood BM. Respiratory syncytial virus infection in tropical and developing countries. Tropical Medicine \& International Health 1998; 3: 268-280.

4. Mentel R, et al. Molecular and clinical characteristics of respiratory syncytial virus infections in hospitalized children. Medical Microbiology and Immunology 2005; 194: 67-71.

5. Welliver R. The relationship of meteorological conditions to the epidemic activity of respiratory syncytial virus. Paediatric Respiratory Reviews 2009; 10 (Suppl. 1): 6-8.

6. Yusuf S, et al. The relationship of meteorological conditions to the epidemic activity of respiratory syncytial virus. Epidemiology and Infection 2007; 135: 1077-1090.

7. Rodriguez-Martinez CE, Sossa-Briceno MP, AcunaCordero R. Relationship between meteorological conditions and respiratory syncytial virus in a tropical country. Epidemiology and Infection 2015; 143: 2679 2686.

8. Bogota's Air Quality Network. Department of the Environment of Bogota (http://ambientebogota.gov.co/ red-de-calidad-del-aire). Accessed 8 July 2015.

9. Glynn RJ, Buring JE. Ways of measuring rates of recurrent events. British Medical Journal 1996; 312: 364-367.

10. Newey WK, West KD. A simple, positive semi-definite, heteroskedasticity and autocorrelation consistent covariance matrix. Econometrica 1987; 55: 703-708.

11. Ralston SL, et al. Clinical practice guideline: the diagnosis, management, and prevention of bronchiolitis. Pediatrics 2014; 134: e1474-1502.

12. Ucrós S, Dueñas E, Gutiérrez M. Seasonal variation of respiratory diseases in Santa $\mathrm{Fe}$ de Bogotá [in Spanish]. Revista Colombiana de Neumologia 1997; 9: 124-132.

13. Lowen AC, et al. Influenza virus transmission is dependent on relative humidity and temperature. PLoS Pathogens 2007; 3: 1470-1476.

14. Schaffer FL, Soergel ME, Straube DC. Survival of airborne influenza virus: effects of propagating host, 
relative humidity, and composition of spray fluids. Archives of Virology 1976; 51: 263-273.

15. Omer SB, et al. Climatic, temporal, and geographic characteristics of respiratory syncytial virus disease in a tropical island population. Epidemiology and Infection 2008; 136: 1319-1327.

16. Simoes EA, Carbonell-Estrany $\mathbf{X}$. Impact of severe disease caused by respiratory syncytial virus in children living in developed countries. Pediatric Infectious Disease Journal 2003; 22 (2 Suppl.): S18-20.
17. Daher KA, Selsted ME, Lehrere RI. Direct inactivation of viruses by human granulocyte defensins. Journal of Virology 1986; 60: 1068-1074.

18. Cherian T, et al. Bronchiolitis in tropical South India. American Journal of Diseases of Children 1990; 144: 1026-1030.

19. Bogotá.gov.co. Public Health Surveillance. Alcaldia of Bogota (http://www.saludcapital.gov.co/sitios/Vigilancia SaludPublica/Boletines $\%$ 20ERA/Forms/Vista $\% 20$ boletines \%20ERA.aspx). Accessed 8 July 2015. 